\title{
Análisis y percepción por parte del alumnado del requisito lingüístico en el acceso al Máster de Formación del Profesorado de Educación Secundaria
}

\author{
Antonio R. Raigón Rodríguez y Ángela M. a LARrea Espinar \\ Universidad de Córdoba
}

Recibido: 7 noviembre 2011 / Aceptado: 15 abril 2012

ISSN: $1697-7467$

RESUMEN: El aprendizaje de un segundo idioma ha sido históricamente un aspecto difícil de abordar en España. Como se puede observar en recientes estudios, la capacidad de nuestra población para mantener una conversación en un segundo idioma está en entredicho. El nuevo procedimiento de acceso al Máster de Formación del Profesorado de Educación Secundaria, para el que es necesaria la acreditación de una competencia comunicativa a nivel intermedio (B1) en una segunda lengua, ha puesto de manifiesto esta carencia.

Con este trabajo pretendemos analizar la percepción de estos alumnos en referencia este requisito lingüístico y cómo han podido cumplirlo. Mediante un cuestionario validado y diseñado ad hoc, hemos extraído conclusiones reveladoras acerca de estos dos aspectos. Nos ha parecido interesante estudiar el papel del centro de idiomas de educación superior como herramienta que lleve a cabo la política lingüística de las universidades. En definitiva, hemos podido obtener una imagen global que nos permita prever cómo el proceso de acreditación se acoplará a los nuevos grados.

Palabras clave: EEES, Formación profesorado, enseñanza de idiomas, acreditación de idiomas, MCERL.

Analysis and Students' Perception of the Linguistic Requirement to Access the Posgraduate Cercificate in Education

ABSTRACT: Learning a second language has always been a problem for Spanish students. As it can be drawn from recent studies, the ability to have a conversation in a second language is not common. The new way to access the Máster de Formación del Profesorado de Educación Secundaria, for which it is compulsory to prove a CEF B1 level in a second language, has made obvious this shortage.

With this paper, we intend to analyze the students' perception towards this requirement and how they fulfilled it. We have validated and designed an ad hoc questionnaire in order to obtain revealing results regarding these two aspects. We have studied the role of the Language Centers in Higher Education as the ideal tool to perform these duties in the universities. Finally, we have been able to obtain a global picture on how this requirement will be adapted in the new university degrees.

Keywords: EHEA, Teacher training, language teaching, language certification, CEFRL. 


\section{INTRODUCCIÓN}

En el apartado 4.2 de la Orden ECI/3858/20071' "Condiciones de Acceso al Máster", se indicaba la necesidad de acreditarse el dominio de una lengua extranjera equivalente al nivel B1 del Marco común europeo de referencia para las lenguas: aprendizaje, enseñanza, evaluación (2002). Quedaban exentos de este requisito los alumnos de algunas titulaciones que se imparten parcialmente en otro idioma, como es el caso de las Filologías Extranjeras o Traducción. Como ha ocurrido posteriormente en marco de los nuevos grados universitarios, el requisito lingüístico ha supuesto un enorme contratiempo para un número considerable de solicitantes del Máster de Formación del Profesorado de Educación Secundaria. Muchos de los aspirantes ese año, supieron del requisito en el mismo momento de la preinscripción.

Una de las consecuencias del Plan Bolonia se materializó de repente ante muchos licenciados que se disponían a cursar un Máster que les permitiría presentarse a las oposiciones a cuerpos docentes de enseñanza secundaria. Profesores en ciernes de Química, Lengua, Música o Historia, que habían optado por apartarse del aprendizaje de una segunda lengua desde sus olvidados años de bachillerato. Debían de acreditar un nivel intermedio (B1) en otro idioma, lo cual no tendría que suponer un gran esfuerzo para unos estudiantes que habían pasado buena parte de su formación recibiendo clases de inglés u otra lengua extranjera.

Los niveles de frustración se hicieron patentes en un colectivo que de repente, o al menos esa era su impresión, encontraba una muralla entre ellos y sus legítimas ambiciones.

A pesar de la priorización de la enseñanza de idiomas en las políticas educativas autonómicas y tal y como resalta Lagasabaster (2008), la ciudadanía del Estado español no destaca por su conocimiento de lenguas extranjeras, sino que aparece en los últimos puestos en los estudios realizados por la Comisión Europea y otros organismos sobre el tema (Informe PISA, 2009).

El alumnado español estudia un idioma extranjero desde los ocho años, es decir, unos diez años antes de llegar a la universidad. Según el último estudio europeo del que disponemos, $85.2 \%$ estudia inglés en primaria (13 puntos más que en 1998), 97.1\% lo hace en secundaria, $36.3 \%$ francés y $1.7 \%$ alemán (Eurydice, 2005).

No nos incumbe desarrollar aquí las complejas razones que llevan a que un sistema educativo público se muestre ineficiente en este aspecto, como así demuestran los resultados del último Eurobarómetro (2005: 3) en su apartado "Europeos y los idiomas". Este estudio muestra que el porcentaje de población en España capaz de participar en una conversación en otra lengua es 14 puntos inferior a la media europea y sólo 6 puntos superior a la media en Reino Unido, país que históricamente, y debido a la preeminencia del inglés como lingua franca, ha descuidado este aspecto.

El problema que se plantea en las universidades españolas, y que probablemente se verá agravado conforme se acerque el momento de la graduación de las primeras promociones,

${ }^{1}$ ORDEN ECI/3858/2007, de 27 de diciembre, por la que se establecen los requisitos para la verificación de los títulos universitarios oficiales que habiliten para el ejercicio de las profesiones de Profesor de Educación Secundaria Obligatoria y Bachillerato, Formación Profesional y Enseñanzas de Idiomas. 
es -precisamente- que nuestro desarrollo competencial ha sido tradicionalmente asimétrico, prestando gran atención a las destrezas escritas y dejando a un lado las orales, como demuestran Corpas y Madrid (2009). El alumnado participante en su estudio sobre comprensión oral obtiene un nivel medio de A2, es decir, es tan sólo capaz de entender frases muy simples de su entorno más cercano, siempre y cuando sean pronunciadas de manera clara y lenta. Esto después de estudiar inglés durante diez años.

La escasa literatura relacionada con el requisito lingüístico en los nuevos Grados universitarios se debe a que este tema casi no ha sido tratado en España en profundidad, dada la reciente naturaleza de su implantación. En uno de los pocos trabajos publicados, Cortina demuestra que los estudiantes están muy por debajo del nivel que les será exigido para egresar. Este nivel es aún menor en las destrezas orales. Estos mismos señalan como factor principal "la escasa atención prestada a dicha destreza en las etapas de Primaria, Secundaria y Bachillerato" (2011: 171). Esta autora alude también a la falta de motivación en la etapa preuniversitaria como factor determinante de estos resultados.

\section{El REQUiSITO LINGÜístico DENTRO DEL SISTEMA UNIVERSITARIO}

El alumnado que tenga que acreditar un nivel B1 en una lengua extranjera para obtener su título de Grado tendrá que superar una prueba de idioma que con ligeras variaciones dependiendo de la entidad examinadora contendrá los siguientes apartados:

Tabla 1. Estructura prueba de idioma.

\begin{tabular}{|l|l|}
\hline Sección & Descripción \\
\hline Audición & $\begin{array}{l}\text { Audiciones para evaluar la } \\
\text { comprensión del alumno. }\end{array}$ \\
\hline Lectura & $\begin{array}{l}\text { Textos de lectura para evaluar } \\
\text { la comprensión del alumno. }\end{array}$ \\
\hline Uso del idioma & $\begin{array}{l}\text { Ejercicios destinados a } \\
\text { comprobar el dominio de la } \\
\text { lengua y su estructura } \\
\text { gramatical. }\end{array}$ \\
\hline Escritura & $\begin{array}{l}\text { Realización de una redacción } \\
\text { de tema y formato indicado. }\end{array}$ \\
\hline Expresión oral & $\begin{array}{l}\text { Entrevista oral con un } \\
\text { examinador }\end{array}$ \\
\hline
\end{tabular}

La introducción de este requisito en el Máster de Formación del Profesorado de Educación Secundaria, ha supuesto que muchos de los aspirantes hayan encontrado algunas dificultades (en el mejor de los casos) para superar pruebas de idioma de estas características. 
Las universidades españolas han empezado a contar con sus centros de idiomas muchos de los cuales se encuentran asociados en $\mathrm{ACLES}^{2}$ para dar respuesta a este problema. Estos centros son, normalmente, estructuras más flexibles que las propias universidades y son capaces de dar respuestas más ágiles a circunstancias cambiantes. La dedicación de estas organizaciones en exclusividad a la enseñanza instrumental de la lengua supone otra ventaja. Tampoco debemos olvidar que la enseñanza de idiomas a menudo se ve perjudicada dentro de la enseñanza superior reglada por el alto número de alumnos por clase. Esta circunstancia hace que, como de costumbre, se descuiden las destrezas orales, sobre todo la productiva, por falta de grupos que favorezcan otro tipo de actividades más participativas. Por otra parte, al alumnado le supone un menor esfuerzo participar en grupos más reducidos, ya sea por timidez o por falta de autoestima en lo que se refiere al dominio de otro idioma.

Al igual que los anteriormente mencionados centros han estado años promoviendo la enseñanza de idiomas a cambio de créditos de libre configuración, ahora han de jugar un papel importantísimo en el proceso de acreditación.

En este sentido, muchos de ellos llevan trabajando varios años para dar respuesta a las nuevas necesidades:

- Participando como instituciones organizadoras de exámenes de acreditación de reconocido prestigio internacional como TOEFL, ESOL, IELTS y Trinity, en el caso del inglés.

- Orientando el sistema de enseñanza propio a la obtención de acreditaciones por medio de tres vías: preparación a través de cursos intensivos, cursos regulares (ambos acompañados por una prueba de acreditación final) y las ejecución de pruebas propias de acreditación de acuerdo con lo expuesto en el MCERL (2002).

- Informando a la comunidad universitaria acerca del nuevo requisito lingüístico, tratando de clarificar algunos aspectos relacionados con la acreditación de idiomas.

Este escenario nos hizo plantearnos cómo la universidad podía hacer frente a este panorama. Es, por tanto, el objetivo principal de este estudio saber si estos medios habían llegado a la comunidad universitaria y si el mensaje había calado. No tener cierta claridad y percepción de la verdadera dimensión del problema supondría ir a ciegas en un tema tan serio como los futuros egresados de nuestra Universidad. Es necesario conocer las necesidades y las valoraciones del alumnado, con el fin de adaptar la oferta y redoblar los esfuerzos informativos en caso de detectar esta carencia.

\section{Datos básicos y metodología}

Tal planteamiento nos llevó a querer medir la percepción de los alumnos de la segunda promoción de este Máster (2010-2011) en la Universidad de Córdoba y saber a ciencia cierta cómo habían conseguido acceder al mismo, en lo concerniente al requisito lingüístico. Además de esto, es nuestra intención encontrar opciones de mejora que permitan a esta

\footnotetext{
${ }^{2}$ http://www.acles.es/
} 
institución dar respuesta al gran reto que llegará en dos años académicos, cuando todos los grados cursen su último curso y el alumnado tenga que acreditar este requisito.

\subsection{Participantes}

Durante el año académico 2010-2011, 216 alumnos y alumnas cursaron el Máster de Formación del Profesorado de secundaria de la Universidad de Córdoba. De estos 216 matriculados, 173 realizaron la encuesta, 102 mujeres (59\%) y 71 hombres $(41 \%)$. La distribución de los sujetos en relación a la titulación de procedencia es la siguiente, indicando tan sólo las más frecuentes:

Tabla 2. Distribución por titulaciones de la muestra.

\begin{tabular}{|l|c|}
\hline TITULACIÓN & $\%$ \\
\hline LADE & 12,7 \\
\hline FILOLOGÍA INGLESA & 9,1 \\
\hline $\begin{array}{l}\text { TRADUCCIÓN E } \\
\text { INTERPRETACIÓN }\end{array}$ & 7,1 \\
\hline INGENIERÍA INDUSTRIAL & 6,4 \\
\hline HISTORIA & 5,8 \\
\hline BELLAS ARTES & 5,2 \\
\hline MÚSICA & 5,2 \\
\hline PSICOLOGÍA & 4,6 \\
\hline $\begin{array}{l}\text { ARQUITECTURA Y ARQ. } \\
\text { TÉCNICA }\end{array}$ & 4,0 \\
\hline INFORMÁTICA & 4,0 \\
\hline QUÍMICA & 3,5 \\
\hline TURISMO & 3,5 \\
\hline
\end{tabular}


Alumnado según su universidad de procedencia:

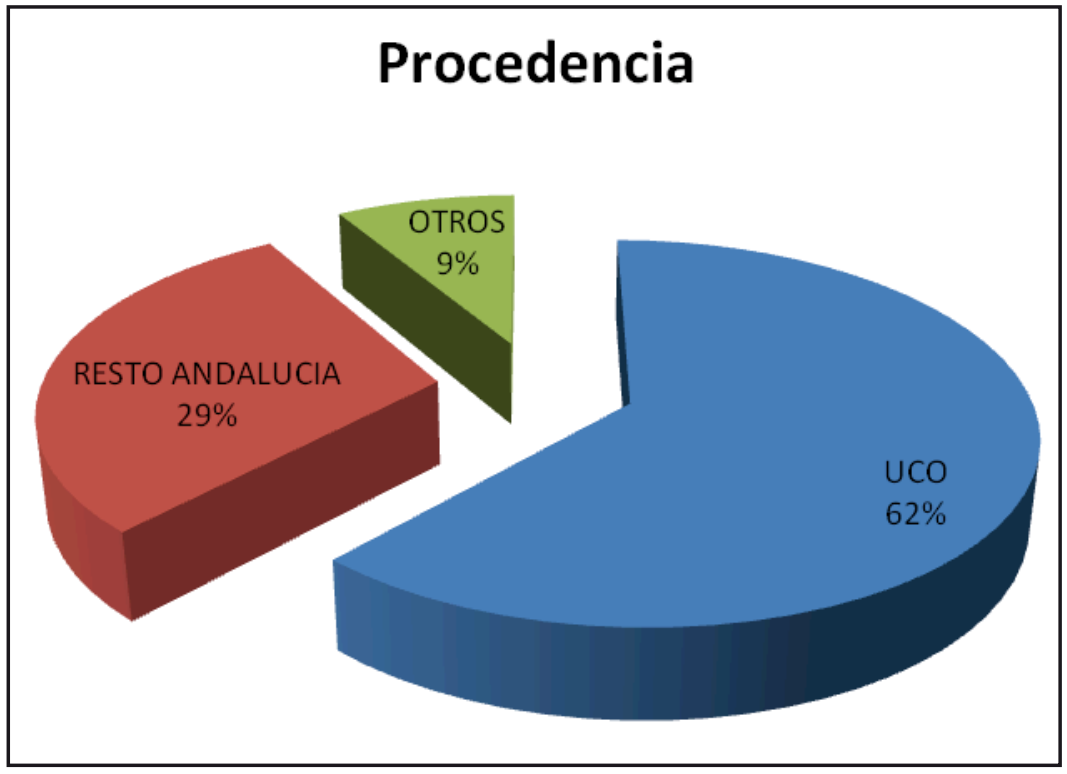

Figura 1. Distribución de la muestra por procedencia.

\subsection{Instrumento}

Hemos realizado un cuestionario ad hoc que consta de cuatro partes:

1. Datos del encuestado.

2. Datos relativos a la acreditación para acceder al Máster.

3. Percepción acerca del servicio prestado por la Universidad y su Servicio de Idiomas.

4. Percepción del papel del requisito en relación con el Máster.

Para poder determinar la validez y fiabilidad del instrumento diseñado para este estudio se han realizado diferentes procesos y análisis. Respecto a la validez de contenido, se ha practicado un juicio de expertos, en relación a los procesos seguidos para dotar de fiabilidad al instrumento, se ha utilizado un enfoque de consistencia interna (Morales, P., 2008) y un análisis de la capacidad de discriminación de los ítems de modo que se fortalezca el carácter unidimensional de la prueba.

El juicio de expertos estaba constituido por ocho profesionales de las Universidades de Córdoba, Jaén y Granada de diferentes escalas docentes e investigadoras de la educación superior, los cuales valoraron los ítems en relación a la claridad (precisión en la forma de redactar el ítem para la comprensión de los encuestados) y pertinencia (correspondencia entre el contenido del ítem y la dimensión) de los mismos para el estudio. La escala Likert 
empleada fue expresada con un rango de 1 a 5 , donde 1 significaba mínima valoración y 5 máxima valoración. Los resultados revelados al aplicar un análisis con estadísticos descriptivos de tendencia central, tanto en la pertinencia como en la claridad de los ítems ha sido de máxima valoración (todos por encima de valores $\bar{\chi}=4$ ), sobresaliendo los ítems 5,6 y $15(\bar{\chi}=5,00$ en todos los ítems respecto a la pertinencia y claridad) y disminuyendo la valoración en el ítem 16 ( $\bar{\chi}=4,37$ pertinencia y 4,38 claridad).

Referente a la fiabilidad a través del enfoque de consistencia interna (Morales, P. 2008), el resultado obtenido al aplicar el procedimiento de Alfa de Cronbach ha sido de 0, 890, lo cual refleja una fiabilidad alta de los ítems expresados en el cuestionario. En este sentido, buscando la fortaleza en el carácter unidimensional de la prueba (índice de fiabilidad) se ha realizado un análisis de la capacidad de discriminación de los elementos a través de la prueba estadística $t$ de Student (para muestras independientes) entre las medias de los grupos establecidos, revelando un alto poder de discriminación en todos los ítems (valores de significatividad $\mathrm{p}=0,000$ ), lo cual implica que los elementos recogidos en la prueba cumplen con los objetivos planteados para cada una de las cuestiones de la dimensiones.

\subsection{Procedimiento}

El cuestionario fue administrado a los alumnos aprovechando la celebración de un módulo común celebrado en la Facultad de Ciencias de la Educación de la Universidad de Córdoba. Este se realizó simultáneamente a los cuatro grupos en los que estaban divididos el total de los alumnos encuestados, asegurando el anonimato de los participantes. Se solicitó permiso del Vicerrectorado de Estudios de Postgrado y Formación Continua para la realización del mismo.

\section{Resultados}

Los resultados más relevantes que hemos podido obtener después de analizar las cifras son los siguientes:

- El 83.8\% de los participantes hubo de acreditar un nivel B1 en una segunda lengua como requisito de acceso. El resto corresponden a las licenciaturas exentas.

- Sólo tres de cada diez había obtenido su acreditación por otro motivo que no fuera el acceso al Máster. Es decir, la mayoría de los estudiantes no se planteó previamente certificar su competencia lingüística. 


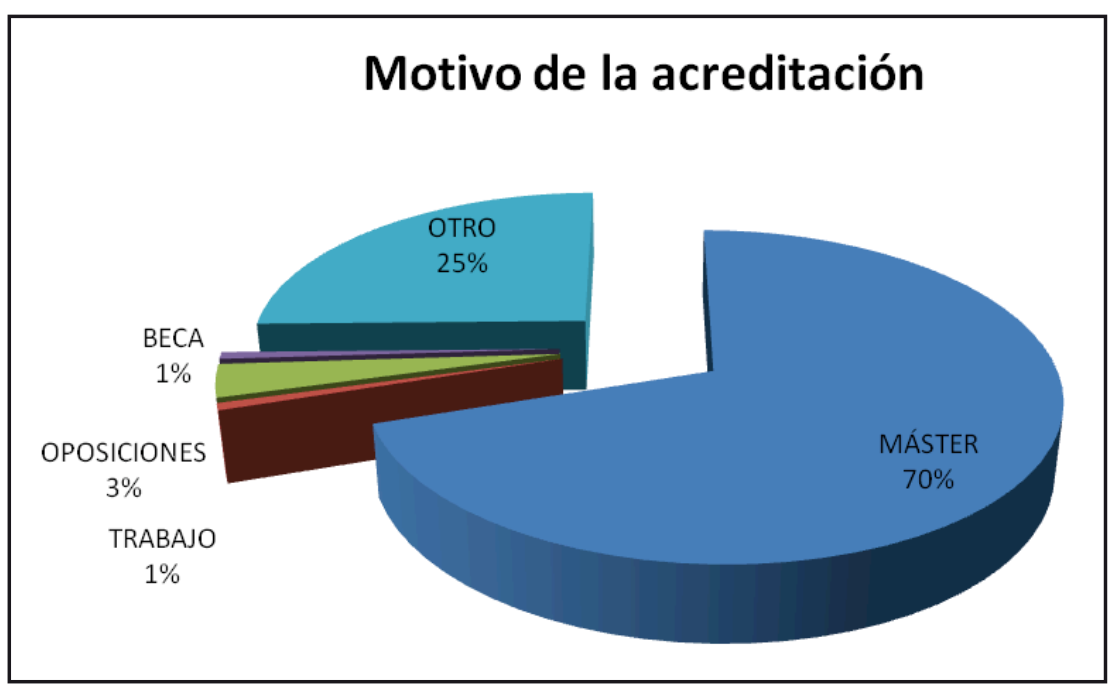

Figura 2. Motivo de la obtención de la acreditación.

- Siendo el nivel B1 el mínimo, sólo un 19.6\% obtuvo un nivel superior.

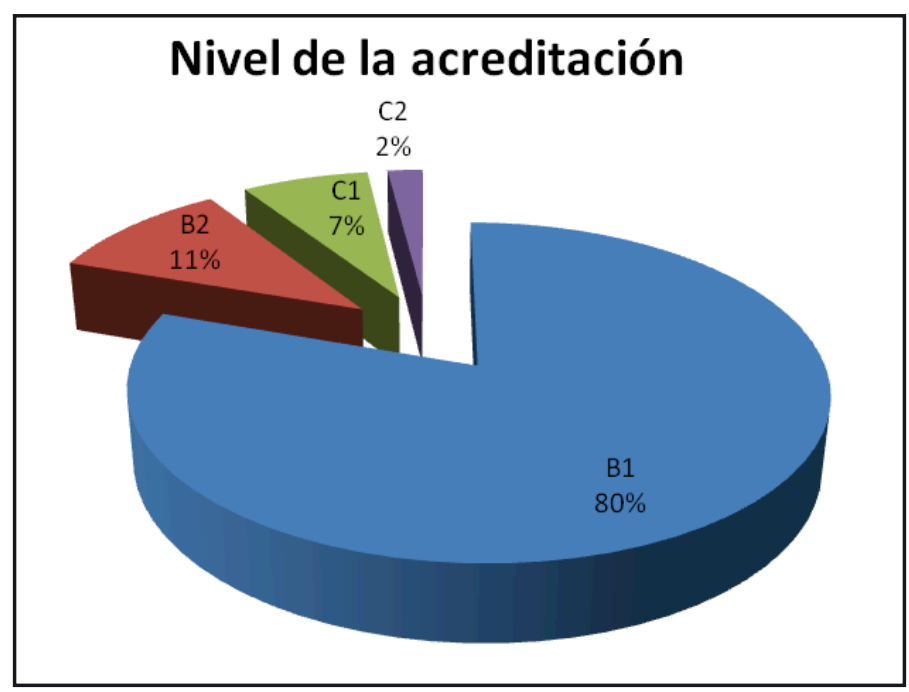

Figura 3. Nivel acreditado por el alumnado.

- Un 92.2\% de los estudiantes se inclinó por el inglés como idioma para acreditar su competencia en una segunda lengua. 


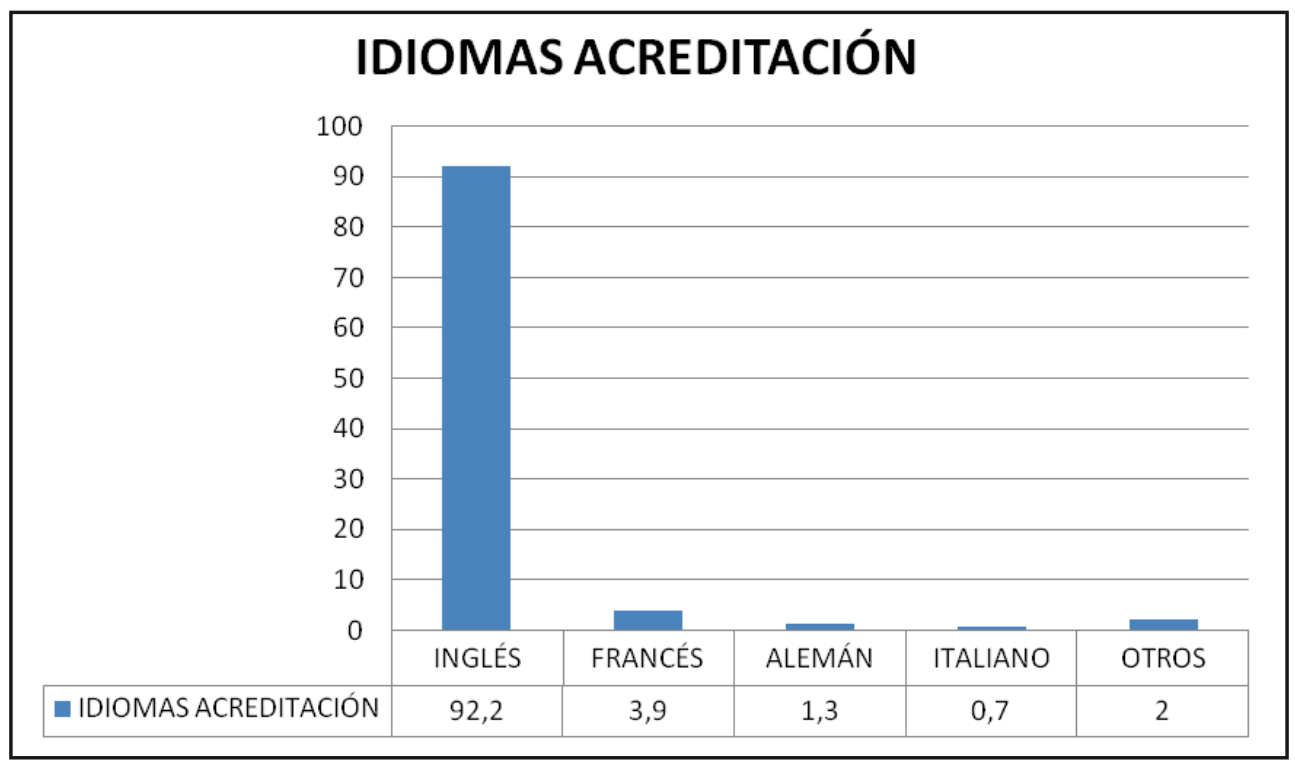

Figura 4. Distribución de acreditaciones por idiomas.

- El 73.5\% de los estudiantes que acreditó a través de este idioma lo hizo a través de Ucoidiomas (Centro de idiomas de la Universidad de Córdoba): $27.3 \%$ a través del examen propio en convocatoria libre, $37.8 \%$ tras cursos intensivos de preparación y $8.4 \%$ tras formarse en los cursos regulares.

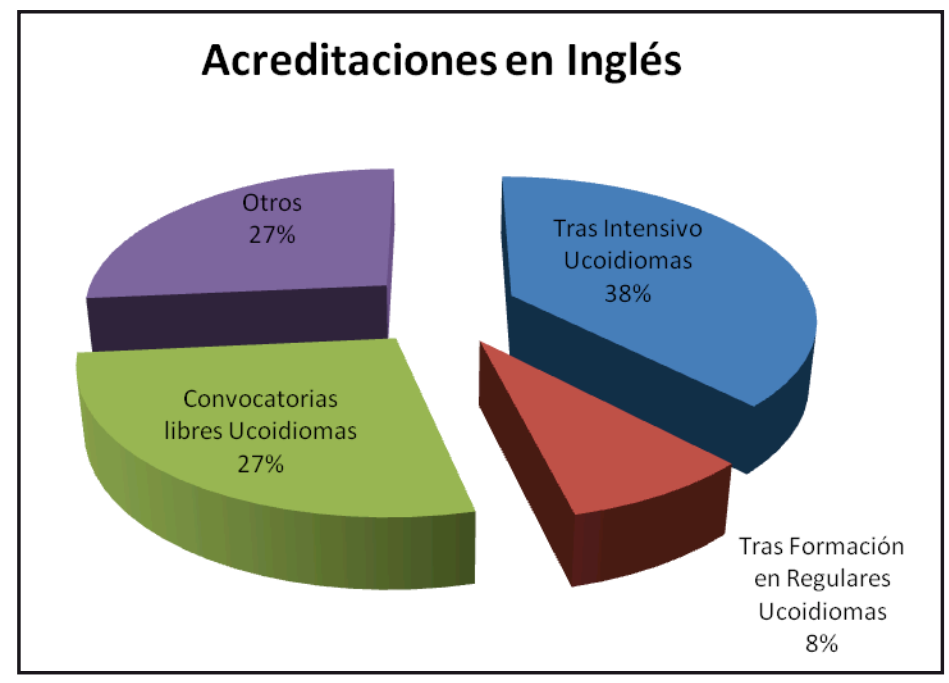

Figura 5. Distribución de las acreditaciones en lengua inglesa. 
- Como aspectos menos valorados por los estudiantes, se encuentra el precio de los servicios y la poca relevancia de una segunda lengua para el Máster. Por otro lado, los alumnos estiman que el dominio de otro idioma mejora su formación académica y docente.

Tabla 3. Análisis de la percepción por items.

\begin{tabular}{|c|c|c|c|}
\hline & $\mathrm{N}$ & Media & Desv. típ. \\
\hline $\begin{array}{l}\text { 1. La información recibida por parte de la UCO relativa } \\
\text { a la acreditación B1 ha sido la adecuada. }\end{array}$ & 128 & 2,83 & 1,293 \\
\hline $\begin{array}{l}\text { 2. La información recibida en Ucoidiomas ha sido } \\
\text { correcta. }\end{array}$ & 115 & 3,19 & 1,290 \\
\hline $\begin{array}{l}\text { 3. La variedad de la oferta de acreditaciones en } \\
\text { Ucoidiomas es oportuna. }\end{array}$ & 113 & 3,15 & 1,189 \\
\hline $\begin{array}{l}\text { 4. La cantidad de convocatorias de pruebas de } \\
\text { acreditación en Ucoidiomas es adecuada. }\end{array}$ & 115 & 2,97 & 1,224 \\
\hline $\begin{array}{l}\text { 5. El precio de los cursos en Ucoidiomas es adecuado } \\
\text { (contesta sólo si has sido usuario). }\end{array}$ & 84 & 1,80 & 1,050 \\
\hline $\begin{array}{l}\text { 6. El precio de los exámenes en Ucoidiomas es } \\
\text { adecuado (contesta sólo si has sido usuario). }\end{array}$ & 97 & 1,95 & 1,084 \\
\hline $\begin{array}{l}\text { 7. Los servicios ofrecidos en Ucoidiomas han sido } \\
\text { acordes a lo esperado. }\end{array}$ & 114 & 2,93 & 1,173 \\
\hline $\begin{array}{l}\text { 8. El dominio de otra lengua es necesario para asimilar } \\
\text { algunos contenidos de este Máster. }\end{array}$ & 156 & 1,85 & 1,240 \\
\hline $\begin{array}{l}\text { 9. La exigencia de este requisito lingüístico es } \\
\text { importante para favorecer la calidad del Máster. }\end{array}$ & 154 & 2,34 & 1,425 \\
\hline $\begin{array}{l}\text { 10. El dominio de otra lengua es relevante para el } \\
\text { desarrollo de mi futura labor como docente. }\end{array}$ & 156 & 3,67 & 1,354 \\
\hline $\begin{array}{l}\text { 11. El dominio de otro idioma mejorará mi formación } \\
\text { académica. }\end{array}$ & 156 & 4,14 & 1,231 \\
\hline
\end{tabular}

Sin duda alguna, los aspectos menos valorados por el alumnado son el precio de los exámenes y de los cursos ( $\mathrm{x}=1,95$ y 1,80 , respectivamente) y la relación entre el máster $\mathrm{y}$ el requisito lingüístico $(\mathrm{x}=1,85)$. El alumnado percibe que el requisito está desconectado por completo de la realización del Máster. Paradójicamente, afirman mayoritariamente que el dominio de otro idioma mejorará su formación académica $(\mathrm{x}=4,14)$ y los hará mejores docentes $(X=3,67)$.

Los servicios ofrecidos por Ucoidiomas son valorados bastante positivamente en lo que respecta a la información $(X=3,19)$, la variedad de oferta de acreditaciones $(X=3,15)$ y su cantidad $(X=2,97)$.

Aplicada la prueba de significación $t$ de Student $(n . s=0,05)$ en relación a la variable de universidad de procedencia (Universidad de Córdoba u otra) y las percepciones en relación a la acreditación para el máster no se han evidenciado diferencias significativas. Igualmente, no son significativas las diferencias obtenidas en relación a la variable sexo. 
Análisis y percepción por parte del alumnado...

\section{Conclusiones}

Los resultados obtenidos sugieren la necesidad de una mejora metodológica estructural en todos los niveles educativos, incluido el universitario, donde los estudiantes necesitan información más clara y menos trabas administrativas.

En relación a la dificultad experimentada por el alumnado en secundaria, Pérez-Llantada (2007: 102) señala que las destrezas orales no se evalúan a nivel curricular y esto conlleva un peor rendimiento. Esta misma autora también habla de la motivación, la contextualización y el uso de tareas auténticas como propuestas de mejora en este área del aprendizaje de idiomas. Ciertamente, los alumnos desarrollan mejor las tareas propuestas si ven una aplicación práctica factible. La necesidad que tienen los alumnos de observar un propósito a las tareas desarrolladas en el aula de lenguas ha sido sistemáticamente descuidada en España.

Esta utilidad y propósito inmediatos son señalados por muchos autores (Ayrei, 2004; Coyle, 2004; Marsh, 2008) como una de los pilares más beneficiosos y motivadores del Aprendizaje Integrado de Contenidos y Lenguas Extranjeras (AICLE). No debemos olvidar que los factores emocionales juegan un papel fundamental en el aprendizaje de un idioma extranjero

Pavón y Rubio (2010) indican que los pobres resultados dentro del aula de secundaria pueden estar relacionados con factores como el número de alumnos por clase, la falta de medios y formación metodológica del profesorado de idiomas, o la actitud social de desdén hacia la importancia de las lenguas en los medios de comunicación. Además, no dejan pasar la oportunidad de incidir en la idea de Pérez-Llantada de que, en la práctica, se pone en funcionamiento un "currículo oculto" en secundaria como consecuencia de que la prueba de acceso a la universidad sólo evalúa destrezas escritas. Esto deja el proceso de enseñanza-aprendizaje a medias, ya que, siguiendo a Byram, "... if it is not tested, it is not taught" (2000: 1).

Otra de las conclusiones que obtenemos de nuestro estudio es la cada vez mayor predominancia del inglés como único representante de nuestro vano intento plurilingüe. En realidad, estos datos contradicen el espíritu europeo de respeto a la diversidad lingüística como patrimonio enriquecedor de nuestra cultura (Vez, 2009). El estatus del inglés como lingua franca no hace sino debilitarnos y empobrecernos. Sin embargo, resulta difícil obviar los principios pragmáticos que moldean esta realidad.

Nos encontramos en una disyuntiva en la que, por un lado, aparece el inglés como lingua franca indiscutible en este mundo global (Vez y González, 2004). Por otro lado, el fin prioritario reflejado en el MCERL es defender que "...las distintas lenguas y culturas de Europa constituyen un recurso común muy valioso que hay que proteger y desarrollar." (2002: 13). Es por esto que se debe considerar si los beneficios del AICLE arriba mencionados, no contribuirán, por otra parte, a desequilibrar más la balanza hacia el inglés.

En cuanto a las mejoras a nivel universitario, durante este último año se está trabajando intensamente en un sistema de control y reconocimiento recíproco por parte de muchas instituciones. En el ámbito andaluz, el 2 de julio del 2011 se firmó un convenio de colaboración para la acreditación de lenguas extranjeras por parte de todas las universidades de esta comunidad. Este convenio tiene como fin coordinar la acreditación de niveles de idiomas dentro de Andalucía, estableciendo un procedimiento comúnmente acordado que define un modelo para la realización de pruebas de acreditación de dominio lingüístico de lenguas extranjeras. 
Asimismo a nivel nacional, ACLES se encuentra trabajando en un sistema de reconocimiento mutuo de acreditación entre las entidades participantes, anterior en el tiempo al andaluz.

Es fácil prever que si no se producen los cambios estructurales necesarios en etapas educativas anteriores, la falta de competencia en un segundo idioma se hará patente en los últimos años de formación universitaria del alumnado, cuando haya que acreditar formalmente un nivel B1 en una lengua extranjera; parece injusto tomar medidas de este tipo al final de su camino, en lugar de situar puntos de control a lo largo del mismo. De no ser así, nos encontraremos con miles de estudiantes que habrán superado todas las asignaturas de su titulación y estarán lejos de graduarse.

\section{REFERENCIAS BIBLIOGRÁFICAS}

Airey J. (2004). "Can you teach it in English? Aspects of the language choice debate in Swedish higher education", en Wilkinson, R. (ed.), Integrating content and language. Meeting the challenge of a multilingual higher education, Maastricht: Maastricht University, 97-108.

Byram, M. (2000). "Assessing intercultural competence in language teaching", en Sprogforum, 18/6: 8-13.

Corpas, M. y Madrid, D. (2009). "Desarrollo de la Comprensión Oral en Inglés como LE al Término de la Educación Secundaria Obligatoria española", en Porta Linguarum 11: 129-145.

Cortina, B. (2011). "La expresión oral en lengua inglesa de los futuros maestros: un reto para el Espacio Europeo de Educación Superior", en Porta Linguarum 16: 155-177.

Coyle, D. (2004). "Supporting students in CLIL contexts: Planning for effective classroom", en J. Masih (ed.), Learning through a Foreign Language. Lancaster: CILT, 40-54.

European Commission. (2005). Eurobarometer 237-Wave 63.4, Europeans and Languages Accesible en http://ec.europa.eu/public_opinion/archives/ebs/ebs_237.en.pdf (último acceso 14 septiembre 2011).

Eurydice (2005). Key data on teaching languages at school in Europe. Brussels: Eurydice European Unit. Accesible en http://www.eurydice.org/ (último acceso 29 septiembre 2011).

Lasagabaster, D. (2008). "Foreign language competence in content and language integrated courses", en The Open Applied Linguistics Journal Vol.1, pp. 30-41. Accesible en http://www. bentham.org/open/toalj/openaccess2.htm (último acceso 7 septiembre 2011).

Marsh, D. (2008). "Language awareness and CLIL", en J. Cenoz, NH. Hornberger (eds.), Encyclopedia of language and education. Knowledge about language, Volume 6, New York: Springer, 233-246.

Ministerio de Educación, Cultura y Deporte (2002). Marco común europeo de referencia para las lenguas: aprendizaje, enseñanza, evaluación. Madrid: MECD y Grupo ANAYA.

Morales, P. (2008). Investigación en las Ciencias Sociales. Madrid: Universidad Pontificia Comillas. Accesible en http://www.upcomillas.es/personal/peter/investigacion/ Planteamientos gene rales.pdf (último acceso 2 septiembre 2011).

OCDE (2009). Informe PISA. Accesible en http://www.oecd.org/dataoecd/54/12/46643496.pdf (último acceso 2 septiembre 2011).

Pavón, V. y Rubio, F. (2010). "Teachers' concerns and uncertainties about the introduction of CLIL programmes", en Porta Linguarum 14: 45-58. 
Pérez-Llantada Auría, M. C. (2007). "Nuevos entornos y nuevos modelos pedagógicos para el aprendizaje de las destrezas orales", en I. de Andrés Monte (coord.), El desarrollo de competencias en Lenguas Extranjeras: Textos y otras estrategias. Madrid: Ministerio de Educación, Secretaría General Técnica, 99-119.

Vez, J. M. (2009). "Multilingual education in Europe: policy developments", en Porta Linguarum 12: 7-24.

Vez, J. M. y González Piñeiro, M. (2004). "Intercultural competence and the european dimension", en D. Madrid y N. McLaren (eds.). TEFL in Primary Education. Granada: Universidad de Granada, 342-384. 